\title{
Saffron yield and quality as influenced by different irrigation methods
}

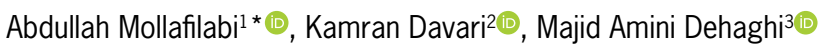

\author{
${ }^{1}$ Research Institute of Food Science and Technology - Dept. \\ of Food Biotechnology, km 12 Mashhad, Quchan Highway - \\ PO Box 91895 - 157356 - Mashhad - Iran. \\ ${ }^{2}$ Ferdowsi University of Mashhad - Dept. of Water Science \\ and Engineering, Azadi Square, Mashhad - 9177948974 - \\ Razavi Khorasan Province - Iran. \\ ${ }^{3}$ Shahed University/Agricultural College - Dept. of Agronomy \\ and Plant Breeding, Persian Gulf Highway - 3319118651 \\ -Tehran - Iran. \\ *Corresponding author <mollafilabi.abdullah@gmail.com>
}

Edited by: Mohammad Valipour

Received April 14, 2019

Accepted September 24, 2019

\begin{abstract}
Dried stigma of saffron is the most expensive spice in the world. In Iran, the majority of saffron farms use the traditional basin method for irrigation, which, together with other irrigation methods may soon face serious problems because of droughts in the future. Making an evaluation of the regional crop response to the irrigation method is important to the adoption of a proper irrigation management strategy. In this study, the effect of employing different irrigation methods, including the sprinkler, drip, furrow, and basin, on the following factors was evaluated: the saffron stigma dry weight, quality, water use efficiency (WUE), and Irrigation water use efficiency (IWUE) in the arid climate of Qaen, South Khorasan, Iran, over three consecutive crop years. The experiment was undertaken using a randomized complete block design with three replications. The results showed that seasonal saffron Evapotranspiration (ETC) was recorded as 356.5, 339.1, and $330.7 \mathrm{~mm}$, in 2003, 2004 and 2005 respectively, as a result of administering the treatments. Saffron yield as well as WUE and IWUE were found to respond to the various irrigation methods except in the first year. In total, maximum stigma dry weight and water use efficiencies were reached in the third growing season using the drip irrigation method. Judging by the results, the drip irrigation method for saffron production is to be preferred. Additionally, the quality level of saffron was found to be acceptable. However, due to higher crocin content, the quality of saffron irrigated by the sprinkler method was somewhat higher.
\end{abstract}

Keywords: crocin, picrocrocin, safranal, drip irrigation, water use efficiency

\section{Introduction}

Dried stigma of Saffron Crocus sativus L., is the most expensive spice in the world, and the most valuable industrial medical crop (Kyriakoudi et al., 2015; Vahedi et al., 2018). In addition to its highly beneficial therapeutic value, saffron is also used as a coloring agent (Koocheki, 2004). Saffron is an indigenous crop of Iran; accordingly, Iran is ranked first in this crop in terms of both area under cultivation and production rate (Vahedi et al., 2018). Afghanistan, Greece, Morocco, India, Spain, and Italy are other producers of saffron though their production levels are negligible (Kafi et al., 2018). According to statistics published by the Ministry of Agriculture, in 2017, saffron dry stigma production in Iran, with a cultivation area of about 105,000 ha, amounted to $336 \mathrm{t}$ accounting for approximately $89 \%$ of total world production. The province of South Khorasan is one of the most important saffron producing regions in Iran Thus, the cultivation of saffron makes a significant contribution to the economy of the province.

Generally, in South Khorasan, saffron is subjected to the traditional basin irrigation method. Regrettably, traditional growers irrigate the saffron regardless of the amount of available water in the soil so that in most cases irrigation is characterized by high volumes with high frequency. Consequently, in addition to wasting water, it can also lead to water stress. Under such a system, saffron fields are routinely irrigated from mid-Oct to early Nov. During this period, pre-flowering irrigation plus 4-6 additional irrigation sessions during the entire plant growth season from Oct up to mid-spring is a common occurrence in South Khorasan (Ghorbani and Koocheki, 2017).
The average annual water requirement for saffron cultivation has been estimated to reach $490 \mathrm{~mm}$ by the year, 2040 due to declining atmospheric precipitation (Jafarzadeh et al., 2015). Yarami et al. (2011) reported that total saffron potential evapotranspiration values were 523 and $640 \mathrm{~mm}$ in the first and second growing seasons, respectively. Thus, due to the shortage of water resources in the future, the efficiency of irrigation water should be increased to meet the water requirement of saffron.

Research has shown that, water use efficiency (WUE) varies under different irrigation systems. AziziZohan et al. (2009) in their study concluded that the basin irrigation method had more WUE than the furrow irrigation method for saffron production. Since saffron is generally cultivated by the basin irrigation method, this form of irrigation has been at the center of attention in most studies. Consequently, information on the WUE for other alternative irrigation methods, such as sprinkler and drip systems is lacking.

Thus, the present study was aimed at evaluating the effect of different irrigation methods on the growth and yield of saffron, as well as water use efficiency in the semi-arid climate.

\section{Materials and Methods}

A field study was conducted for three years in Qaen, South Khorasan province, Islamic Republic of Iran. The area is located at $33^{\circ} 43^{\prime} \mathrm{N}, 59^{\circ} 11^{\prime} \mathrm{E}$, and $1,372 \mathrm{~m}$ above sea level, with warm and dry summers, relatively cold winters and a huge difference between day and night temperatures. According to Emberger's classification, the climate of the region is defined as arid and cold. The mean 
annual temperature and rainfall were equal to $18.2^{\circ} \mathrm{C}$ and $190.3 \mathrm{~mm}$, respectively. The mean yearly maximum and minimum air temperature varies between $37.4{ }^{\circ} \mathrm{C}$ and $-29.6^{\circ} \mathrm{C}$. The soil texture was sandy clay.

\section{Farm preparation}

At the beginning of the first growing season in late May 2003, the soil was plowed, and $10 \mathrm{t} \mathrm{ha}^{-1}$ cow manure plus $150 \mathrm{~kg} \mathrm{ha}^{-1}$ triple superphosphate, and $200 \mathrm{~kg} \mathrm{ha}^{-1}$ potassium sulfate were added to the field according to the soil analysis results (Table 2). Subsequently, the soil was re-plowed and tilled by a disc harrow. In early June 2003, after disinfection using Propargite, saffron corms, each with a mean weight of $8 \mathrm{~g}$, were planted at a depth of $10-15 \mathrm{~cm}, 4-\mathrm{cm}$ apart in rows. The rows were $50 \mathrm{~cm}$ apart. The experimental treatments consisted of the sprinkler, drip, furrow, and basin irrigation methods. The experiments were conducted in a complete randomized block design with three replications and the area of each experimental plot was equal to $15 \mathrm{~m}^{2}$, with 6 rows of $5 \mathrm{~m}$ long. For the furrow irrigation method, the corms were planted on both sides of the ridges, and the distance between the ridges was equal to $50 \mathrm{~cm}$. For the drip and sprinkler methods, the necessary facilities were installed on Aug 5, 2003. The corm weight was measured in early June concurrent with the start of the corm dormancy period.

\section{Implementation of the irrigation systems}

The irrigation water was applied using a flexible hose attached to an electromotor and a volumetric flow meter. Field capacity was determined by installing a number of gypsum blocks (Figure 1). In each crop year, irrigation was carried out on 5 occasions. The first irrigation was carried out in the second week of Oct. and at each event, irrigation continued to reach field capacity. The same treatments were applied during the second and third growing seasons. For the first growing season (2003), after irrigation, the amount of water consumed was measured for sprinkler, drip, furrow, and basin treatments as 375 , 600,750 , and $670 \mathrm{~m}^{3} \mathrm{ha}^{-1}$, respectively. For the second growing season (2004), the amounts mentioned were equal to $550,500,720$, and $870 \mathrm{~m}^{3} \mathrm{ha}^{-1}$, and for the third growing season (2005), they were equal to $460,600,960$, and $1,335 \mathrm{~m}^{3} \mathrm{ha}^{-1}$, respectively. To facilitate the saffron flowering, the surface crust was broken open to a depth of $10 \mathrm{~cm}$ after the first irrigation in each growing season.

\section{Flower harvest}

In each year, flower harvesting began in mid-Nov and continued until early Dec. Every morning before the air became warm, saffron flowers were picked from the surface from an area of $6 \mathrm{~m}^{2}\left(3 \times 2 \mathrm{~m}^{2}\right)$ from each plot, selected at random using a $2 \mathrm{~m}^{2}$ quadrate. The flowers were cleaned, and their stigmas were separated by hand and dried in the shade at room temperature. In the third year, in addition to the flower harvest, leaf fresh weight $\mathrm{m}^{-2}$, leaf dry weight $\mathrm{m}^{-2}$, the average height of 50 saffron plants (selected at random from the middle lines of each plot), and corm dry weight $\mathrm{m}^{-2}$ were also measured. Each year after the flower harvest, $100 \mathrm{~kg} \mathrm{ha}^{-1}$ of urea fertilizer $(46 \% \mathrm{~N})$ was dispersed on the field.

\section{Water use efficiency}

Water use efficiency (WUE, $\mathrm{g} \mathrm{m}^{-3}$ ) and irrigation Water use efficiency (IWUE, $\mathrm{g} \mathrm{m}^{-3}$ ) were calculated as defined in the study by Payero et al. (2008) as follows:

$$
\begin{aligned}
& W U E=\frac{Y}{E T_{o} \times K_{C}} \\
& I W U E=\frac{Y}{I}
\end{aligned}
$$

Tap water valve attached to a flow meter

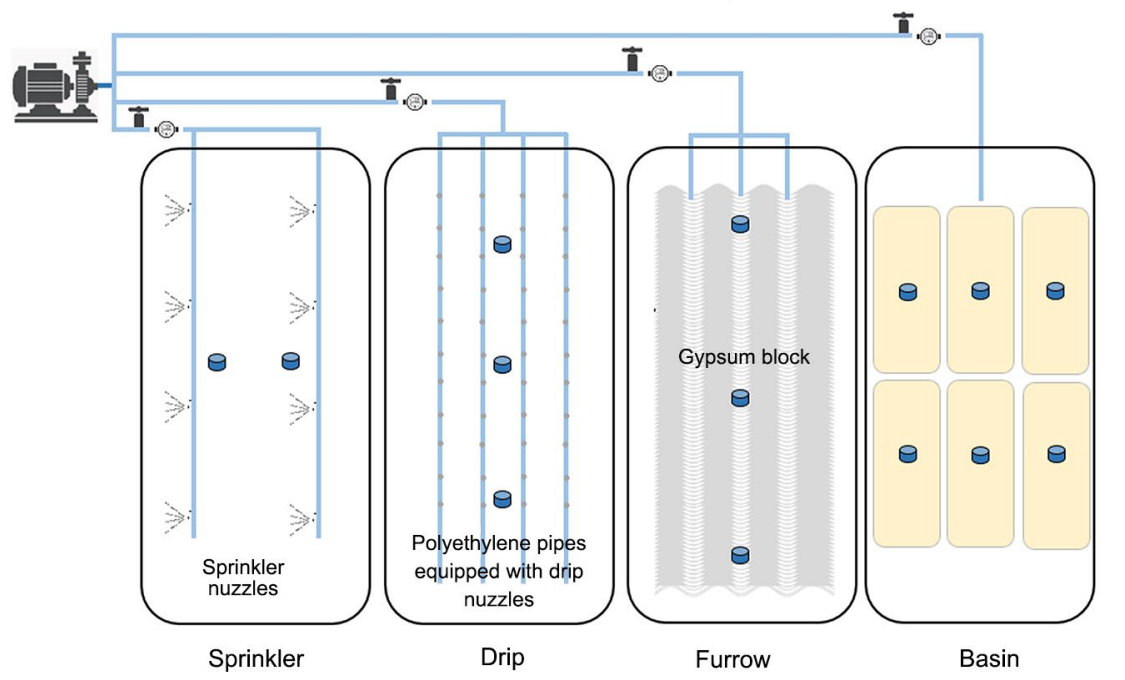

Figure 1 - The overall schematic of the experiment showing the location of the flow meters, gypsum blocks, and sprinkler nozzles installed in the experimental field. 
where $Y$ is the yield (dry stigma, $\mathrm{g} \mathrm{m}^{-2}$ ), $E T_{o^{\prime}}$ the reference evapotranspiration $(\mathrm{mm}), K_{c}$ the crop coefficient, and $I$, the seasonal irrigation $\left(\mathrm{m}^{3}\right)$. The reference evapotranspiration $\left(E T_{0}\right)$ was estimated using the $E T_{0}$ calculator version 3.2 , a computer program developed by $F A O$, Land and Water Division, Rome, Italy. The software supports all measurement units as well as all proposed equations for calculating the $E T_{o}$. The software calculates the $E T_{\text {o }}$ using the weather data as input. In this study, the inputs to the program were monthly weather data, including maximum, minimum, and mean air temperature, actual vapor pressure, wind speed ( $2 \mathrm{~m}$ above soil surface), and actual duration of sunshine during any one day. The necessary meteorological data were obtained from Qaen's meteorological station, from an automatic weather station located within $1.85 \mathrm{~km}$ from the research site. Monthly weather data were downloaded from the IRIMO web site (https://data.irimo.ir). To adjust the estimated $E T_{0^{\prime}}$ the monthly $K_{C}$ proposed in the study by Sepaskhah and Kamgar-Haghighi (2012) was used.

\section{Quality analysis}

Saffron's main components including picrocrocin, safranal, and crocin were determined based on the ISO method (ISO3632-2:2010, saffron-test methods) (Sereshti et al., 2018). Briefly, $50 \mathrm{~mL}$ of distilled water was added to $50 \mathrm{mg}$ of saffron powder $(1 \%, \mathrm{w} / \mathrm{v})$ and was stirred for $1 \mathrm{~h}$. Next, the solution was placed in a dark place for 24 $\mathrm{h}$, then filtered rapidly using filter paper to obtain a clear solution. Then, $1 \mathrm{~mL}$ of this solution was transferred to a 25-mL volumetric flask, and topped up with distilled water $(0.004 \%, w / v)$. Finally, the absorbance of this solution was measured by UV-Vis spectrophotometry. The wavelengths obtained were 330, 440 and $257 \mathrm{~nm}$ for safranal, crocin, and picrocrocine, respectively. The following equation was used to calculate the picrocrocin, safranal, and crocin values:

$$
A_{1 c m}^{1 \%}\left(\lambda_{\max }\right)=\frac{D \times 10000}{M \times\left(100-W_{M V}\right)}
$$

where $D$ is the absorbance of the solution at the desired wavelength; $M$, the Mass of the test portion, $W_{M V}$ the moisture and volatile matter content, expressed as a percentage mass fraction of the sample.

\section{Statistical analysis}

Analysis of variance (ANOVA) and means comparisons were conducted using SAS (Statistical Analysis System, version 9.1) and the PROC GLM test. The means were compared at $5 \%$ probability.

\section{Results and Discussion}

\section{Weather conditions during the growing seasons}

Average values of weather parameters during the period of 2003-2005 for saffron growing seasons in Qaen, South Khorasan, are shown in Table 1. In 2004, the seasonal mean air temperature was higher than that of the two other seasons, which was mainly due to higher minimum temperatures. In 2003, temperatures were higher in Oct-Nov compared to 2004 and 2005 while, in 2005, the seasonal mean actual vapor temperature was higher. On average, wind speed was higher in 2005, and average sunny hours per day was higher in 2003. Total monthly rainfall during the periods of 2003-2005 and 1987-2005, the $E T_{O^{\prime}}$ and the $E_{V}$ (evaporation from class A evaporation pan, $\mathrm{mm} \mathrm{d}^{-1}$ ) for Qaen are shown in Figure 2. The long-term average rainfall diagram shows that rainfall is almost zero from late May to early Oct at the Qaen station. Therefore, as explained before, saffron is one of the best choices for cultivation in the area based on its dormancy and growth periods and water requirements. The annual rainfall recorded was 138.7, 169.5, and 149.2 mm for 2003, 2004 and 2005, respectively. However, the rainfall during all three seasons was less than the period of 1987-2005 (average of $175.76 \mathrm{~mm}$ ). Compared to 2003 and 2005, the 2004 season had less rainfall from Feb to Mar and significant rainfall from Nov to Dec. Therefore, compared to 2003 and 2005, there was a higher chance for more water storage in the soil profile at the beginning of the flowering period in 2004. In the case of saffron cultivation, the amount of water in the soil in Oct and Nov is of particular importance. As shown in Figure
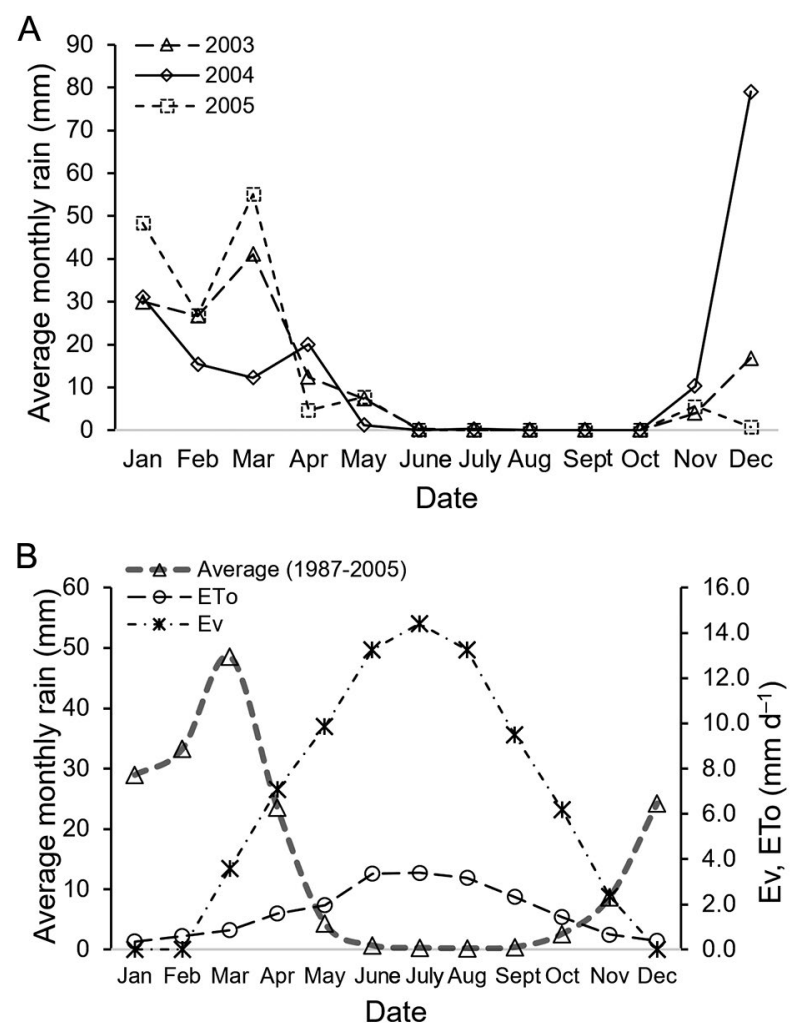

Figure 2 - The average of monthly precipitation (A), daily evaporation from class $A$ evaporation pan (Ev), reference evapotranspiration (ETO) for the period of 2003-2005 and the long-term average precipitation (1987-2005) (B) at Qaen, South Khorasan, Iran. 
Table 1 - The average values of weather parameters during the period of 2003-2005 for saffron growing seasons at Qaen, South Khorasan, Iran.

\begin{tabular}{|c|c|c|c|c|c|c|c|c|c|}
\hline Year & Month & Tmax & Tavg & Tmin & Actual vapor pressure & Wind speed & Total sunny hours & $\mathrm{ET}_{0}$ & $E T_{c}$ \\
\hline & & & $-{ }^{\circ} \mathrm{C}-$ & 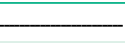 & $\mathrm{kpa}$ & $\mathrm{m} \mathrm{s}^{-1}$ & $\mathrm{~h}$ & $-m$ & $d^{-1}$ \\
\hline \multirow[t]{9}{*}{2003} & Jan & 17.60 & 6.00 & -8.80 & 4.62 & 8.00 & 5.89 & 0.50 & 0.55 \\
\hline & Feb & 19.20 & 8.20 & -6.60 & 5.15 & 12.00 & 7.93 & 0.60 & 0.56 \\
\hline & Mar & 24.40 & 11.70 & -7.80 & 5.65 & 15.00 & 7.06 & 0.70 & 0.48 \\
\hline & Apr & 33.00 & 19.30 & 1.60 & 7.84 & 13.00 & 8.79 & 1.70 & 0.85 \\
\hline & May & 31.80 & 20.90 & 0.40 & 6.99 & 15.00 & 11.02 & 1.80 & 0.76 \\
\hline & Oct & 33.00 & 19.50 & 0.80 & 4.57 & 10.00 & 9.82 & 1.50 & 0.68 \\
\hline & Nov & 27.60 & 9.90 & -9.00 & 3.87 & 8.00 & 8.12 & 0.80 & 0.44 \\
\hline & Dec & 19.00 & 4.80 & -18.20 & 4.30 & 10.00 & 6.27 & 0.30 & 0.28 \\
\hline & Average & 25.70 & 12.54 & -5.95 & 5.37 & 11.38 & 8.11 & 0.99 & 0.57 \\
\hline \multirow[t]{9}{*}{2004} & Jan & 16.20 & 6.40 & -7.80 & 5.95 & 12.00 & 4.66 & 0.30 & 0.33 \\
\hline & Feb & 25.20 & 9.80 & -4.80 & 4.76 & 12.00 & 9.19 & 0.80 & 0.74 \\
\hline & Mar & 28.60 & 14.20 & -1.40 & 5.95 & 13.00 & 7.60 & 1.10 & 0.75 \\
\hline & Apr & 30.60 & 17.50 & 1.40 & 6.27 & 14.00 & 8.53 & 1.50 & 0.75 \\
\hline & May & 33.80 & 24.30 & 3.00 & 6.49 & 15.00 & 10.38 & 1.90 & 0.80 \\
\hline & Oct & 29.20 & 16.60 & -3.40 & 5.16 & 10.00 & 9.91 & 1.20 & 0.54 \\
\hline & Nov & 24.20 & 13.50 & -6.60 & 6.11 & 15.00 & 7.40 & 0.50 & 0.28 \\
\hline & Dec & 16.80 & 5.20 & -7.60 & 5.85 & 8.00 & 4.93 & 0.40 & 0.37 \\
\hline & Average & 25.58 & 13.44 & -3.40 & 5.82 & 12.38 & 7.83 & 0.96 & 0.57 \\
\hline \multirow[t]{9}{*}{2005} & Jan & 14.00 & 1.70 & -17.80 & 4.68 & 10.00 & 6.38 & 0.30 & 0.33 \\
\hline & Feb & 17.80 & 2.50 & -10.60 & 5.16 & 14.00 & 5.19 & 0.40 & 0.37 \\
\hline & Mar & 25.40 & 11.10 & -3.00 & 7.58 & 15.00 & 6.55 & 0.80 & 0.54 \\
\hline & Apr & 30.20 & 15.40 & -3.40 & 7.25 & 11.00 & 9.78 & 1.60 & 0.80 \\
\hline & May & 29.60 & 19.30 & 6.20 & 9.15 & 10.00 & 9.67 & 2.20 & 0.92 \\
\hline & Oct & 33.00 & 15.90 & -2.80 & 5.14 & 8.00 & 9.92 & 1.60 & 0.72 \\
\hline & Nov & 25.00 & 7.60 & -9.80 & 4.78 & 8.00 & 8.52 & 0.70 & 0.39 \\
\hline & Dec & 22.00 & 5.30 & -12.80 & 3.85 & 8.00 & 7.42 & 0.50 & 0.47 \\
\hline & Average & 24.63 & 9.85 & -6.75 & 5.95 & 10.50 & 7.93 & 1.01 & 0.57 \\
\hline
\end{tabular}

Table 2 - Results of the soil analysis of saffron research farm located in suburbs of Qaen, South Khorasan province.

\begin{tabular}{|c|c|c|c|c|c|c|c|c|c|c|c|c|c|c|}
\hline Depth & $\mathrm{pH}$ & EC & $\mathrm{SP}$ & T.N.V & $\mathrm{N}$ & $\mathrm{OC}$ & Sand & Silt & Clay & $P$ & $K$ & $\mathrm{Fe}$ & $\mathrm{Cu}$ & $\mathrm{Zn}$ \\
\hline $\mathrm{cm}$ & & ds $m^{-1}$ & & & & $-\%$ & & & & & & - ppm & & \\
\hline $0-30$ & 8.04 & 0.53 & 22.4 & 18.3 & 0.009 & 0.125 & 86 & 6 & 8 & 1.6 & 120 & 3.08 & 0.16 & 3.02 \\
\hline Optimum & $6-7$ & $<6$ & 40 & $<10$ & $0-100$ & $1-2$ & 40 & 40 & 20 & 20 & 350 & $10-20$ & $0.5-2$ & $3-6$ \\
\hline
\end{tabular}

$\mathrm{EC}=$ electrical conductivity; $\mathrm{SP}=$ saturation percentage; T.N.V = total neutralization value; $\mathrm{N}=$ nitrogen; $\mathrm{OC}=$ organic carbon.

2, the amount of $E T_{O}$ as well as the $E_{V}$ in Oct and Nov was normally higher than the rainfall, justifying the need for irrigation. Furthermore, it was found that the average annual rainfall was equal to $152.47 \mathrm{~mm}$ for the period of 2003-2005, while the average annual $E T_{O}$ was equal to $615.4 \mathrm{~mm}$; thus, $E T_{O}$ was approximately 4 times higher than the rainfall. This result suggests that, with the continuing recent droughts, saffron production will face serious problems if there is any irrigation mismanagement.

\section{Effect of irrigation method on yield and quality of saffron}

The analysis of variance was carried out separately for each year of the experiment. For the first growing season, although the drip irrigation treatment yielded higher stigma dry weight, this superiority was not statistically significant (Figure 2). This may result from the fact that, in this experiment saffron corms were sown only once in the first growing season, and later evaluations in the following years were made on the same corms sown during the first year. Whatsmore, for the first growing season, saffron plants received only irrigation water while in the second and third years, plants received rainfall in addition to irrigation water. Moreover, the variation caused by the irrigation method was masked as a result of the considerable value of experimental error (high differences between the replications belonging to each treatment). Consequently, the test could not identify distinctly the effect of the treatment. In the second and third years, however, the saffron yield responded to the irrigation method, so that stigma dry weight obtained from the drip irrigation method was significantly higher than that of other irrigation methods (Figure 2). In agreement with the results of this study, Karimiferezgh et al. (2018) reported that irrigation of saffron by drip method increased corm dry weight, leaf weight, pod weight, size and number of daughter corms, number of leaves, leaf diameter, leaf length compared to sprinkler and basin irrigation methods. 
The analysis results of the second year data showed that the irrigation method had a significant effect on saffron yield $(p<0.01)$. According to the multiple comparisons of means, three groups were recognized (Figure 2). There was no statistically significant difference between the furrow and basin irrigation methods in the second year, while there were significant differences between the drip irrigation method and the three other methods. Moreover, the sprinkler irrigation method yielded the lowest quantity of saffron stigma dry weight. This may be due to the occurrence of surface crusts, after the first irrigation (maybe due to the soil's low organic matter) resulting in reduced saffron yield. Despite breaking the surface cracks, saffron yield was reduced under the sprinkler irrigation method. There was a similar problem for the furrow irrigation method, while the drip irrigation method resulted in better soil moisture which in turn led to providing a better environment around the saffron corms in terms of moisture content. Furthermore, under the drip irrigation method, surface crusting did not appear to lead to facilitation of the emergence of saffron flowers. The ratios of saffron yield in drip irrigation method to that of the basin, furrow, and sprinkler irrigation methods were equal to $4.21,5.56$, and 7.32 , respectively.

In general, higher crop yield was achieved in the third growing season, once three years had passed from the cultivation in the field, which may be due to the greater number of flower harvest events. The analysis of variance showed that the results were similar to those obtained in the second year. Mean comparisons revealed that there were no significant differences between the furrow, basin, and sprinkler irrigation treatments while the drip irrigation treatment resulted in significantly higher yield (Figure 2). It seems that, similar to what happened in the second year; the formation of surface crusts after each irrigation had a major role in reducing the saffron yield. Azizi-Zohan et al. (2009) believed that, in the furrow irrigation system, the unfavorable soil conditions caused by the thinner soil layer over corms will result in a reduction in the growth of corms and growing periods. In the third growing season, the ratios of saffron yield in drip irrigation method to that in the basin, furrow, and sprinkler irrigation methods were equal to 13.1, 14.1, and 12.32, respectively. Azizi Zohan et al. (2006) proposed that, out of the two methods of irrigation i.e. basin and farrow, the basin is preferred over furrow irrigation due to lower water consumption and production of larger size corms which promotes flowering.

In the third year of the experiment, in addition to measuring stigma dry weight, a number of characteristics related to the growth of saffron were also measured (Table 3). Maximum and minimum corm weight was obtained for the basin and sprinkler irrigation methods, respectively. Similarly, the highest and lowest leaf dry weight was found for the basin and sprinkler irrigation methods, respectively (Table 3). These results revealed that, the drip irrigation method yielded more stigma dry weight (logically a greater number of flowers), but less vegetative growth compared to the basin method. Thus, vegetative growth may be negatively correlated with the reproductive growth and therefore, there may be an antagonistic relationship between these two typ es of saffron traits (Table 3 and Figure 3). The majority of prior research studies have focused on comparisons between basin and furrow irrigation methods. For example, Azizi-Zohan et al. (2009) concluded that the furrow irrigation method provides a higher number of small size corms while basin irrigation method provides a higher number of large size corms. In contrast, Khazaei et al. (2013) achieved a higher corms number and corm weight through the furrow irrigation method compared with the basin irrigation method.

In addition to quantitative measurements, the status of quality characteristics is important in the case of saffron trading. Thus, in this study, certain qualitative indices of saffron were determined (Table 4). The results showed that the quality of saffron obtained under different irrigation methods was at an acceptable level. Although there were a number of differences between the quality characteristics studied, they were not statistically significant. Therefore, the observed differences were presented only numerically (Table 4). The level of picrocrocin content, as the chemical component most responsible for the taste of saffron (Kabiri et al., 2017), and as estimated by the sprinkler and furrow irrigation methods, was high. Furthermore, the Safranal content, as the constituent primarily responsible for the aroma of saffron (Razavi and Hosseinzadeh, 2017),

Table 3 - Comparison of the mean traits related to the vegetative growth of saffron in the third year of the experiment.

\begin{tabular}{lcccc}
\hline Irrigation method & $\mathrm{PH}$ & LFW & LDW & CW \\
\hline & $\mathrm{cm}$ & & $\mathrm{g} \mathrm{m}^{-2}$ & \\
\cline { 3 - 5 } Drip & $34.95 \mathrm{~b}$ & $751.5 \mathrm{ab}$ & $237.75 \mathrm{~b}$ & $751 \mathrm{~b}$ \\
Sprinkler & $37.01 \mathrm{a}$ & $485.5 \mathrm{~b}$ & $184.88 \mathrm{~b}$ & $705 \mathrm{~b}$ \\
Basin & $36.1 \mathrm{ab}$ & $884.5 \mathrm{a}$ & $293.5 \mathrm{a}$ & $1150.2 \mathrm{a}$ \\
Furrow & $35.75 \mathrm{ab}$ & $575.5 \mathrm{~b}$ & $200.06 \mathrm{~b}$ & $849.3 \mathrm{ab}$ \\
\hline
\end{tabular}

Means with different letters are significantly different; $\mathrm{PH}=$ Plant height (the average the height of 50 plants); LFW = Leaf fresh weight; LDW = Leaf dry weight; $\mathrm{CW}=$ Corm weight.

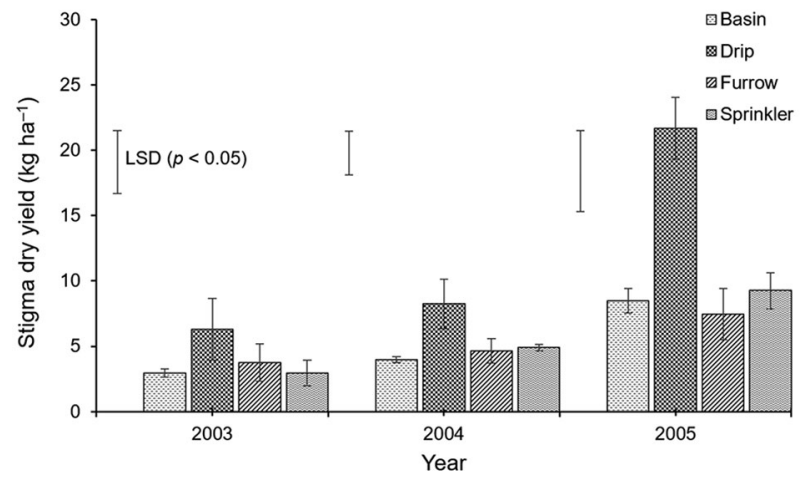

Figure 3 - The effect of different irrigation methods on saffron yield (stigma dry weight) during three growing seasons at Qaen, South Khorasan, Iran. LSD = Least Significant Difference. 
was found to be within the acceptable range (Table 4). Numerically, the drip and furrow irrigation methods were found to have higher safranal content than that of the other two methods. Moreover, as shown in Table 4, the amounts of crocin, the chemical component primarily responsible for the color of saffron (Amini et al., 2017), were also at the standard level. Numerically, the sprinkle irrigation treatment was found to yield a noticeably high crocin level which was more than those measured for other methods. These results indicated that, environmental factors have a significant effect on saffron quality. Therefore, the expression of the genes responsible for saffron quality would be significantly influenced by the environmental conditions. Numerically, saffron irrigated using the sprinkler method showed a higher yield and crocin content, and, consequently, its quality was also noticeably higher (Table 4). No logical justification was found in this regard.

The biplot graph discriminated the distributions of different irrigation methods and the growing seasons based on principal component analysis (Figure 4). The highest value of saffron yield was observed for the drip irrigation method in 2005 (Figure 4A).

Effect of irrigation method on water use efficiency WUE and IWUE for the different irrigation methods are shown in Table 5. Different values were obtained for both IWUE and WUE depending on the irrigation method employed, due to the different amounts of water consumed and the different yield levels obtained at each treatment level (Table 5). Irrigation treatments influenced the IWUE much more than the WUE. However, the difference was not statistically significant between the values of these parameters for the first growing season. This result was not unexpected, since both the IWUE and WUE are calculated based on the yield (the numerator of both equations 1, and 2) and, as previously explained, the saffron yield was not statistically influenced by the irrigation methods in the first growing season. Due to the high level of production

Table 4 - The effect of irrigation methods on quality characteristics of saffron during the period of 2003-2005 for growing seasons at Qaen, South Khorasan, Iran.

\begin{tabular}{lccc}
\hline & Picrocrocin $^{*}$ (absorption at 257 nm) & Safranal $^{*}$ (absorption at 330 nm) & Crocin $^{*}$ (absorption at 440 nm) \\
\hline Sprinkler & 81.22 & 24.32 & 222.98 \\
Drip & 69.39 & 31.29 & 170.5 \\
Furrow & 82.6 & 34.65 & 191.57 \\
Basin & 71.45 & 29.45 & 184.48 \\
\hline Premium saffron & 85 & $20-50$ & 220
\end{tabular}

${ }^{*}$ in each column the data were not, statistically speaking, significantly different.

Table 5 - The effect of irrigation methods on water use efficiency in saffron yield (stigma dry weight) during the period of 2003-2005 for growing seasons at Qaen, South Khorasan, Iran.

\begin{tabular}{|c|c|c|c|c|c|c|}
\hline \multirow{2}{*}{ Treatment } & \multicolumn{2}{|c|}{2003} & \multicolumn{2}{|c|}{2004} & \multicolumn{2}{|c|}{2005} \\
\hline & IWUE & WUE & IWUE & WUE & IWUE & WUE \\
\hline & & & & & & \\
\hline Basin & $4.44 \pm 0.47$ & $0.83 \pm 0.09$ & $4.62 \pm 0.26$ & $1.18 \pm 0.07$ & $10.6 \pm 1.16$ & $2.56 \pm 0.28$ \\
\hline Drip & $11.69 \pm 3.96$ & $1.97 \pm 0.67$ & $16.5 \pm 3.77$ & $2.43 \pm 0.56$ & $44.86 \pm 4.87$ & $6.55 \pm 0.71$ \\
\hline Furrow & $5.01 \pm 1.91$ & $1.05 \pm 0.4$ & $3.68 \pm 1.29$ & $0.78 \pm 0.27$ & $10.66 \pm 2.81$ & $2.26 \pm 0.59$ \\
\hline Sprinkler & $7.89 \pm 2.6$ & $0.83 \pm 0.27$ & $1.59 \pm 0.45$ & $0.26 \pm 0.07$ & $17.79 \pm 2.65$ & $2.8 \pm 0.42$ \\
\hline $\operatorname{LSD}(p<0.05)$ & 9.06 & 2.16 & 6.43 & 0.99 & 11.42 & 1.88 \\
\hline
\end{tabular}

IWUE = Irrigation water use efficiency; WUE = water use efficiency; LSD = Least Significant Difference.
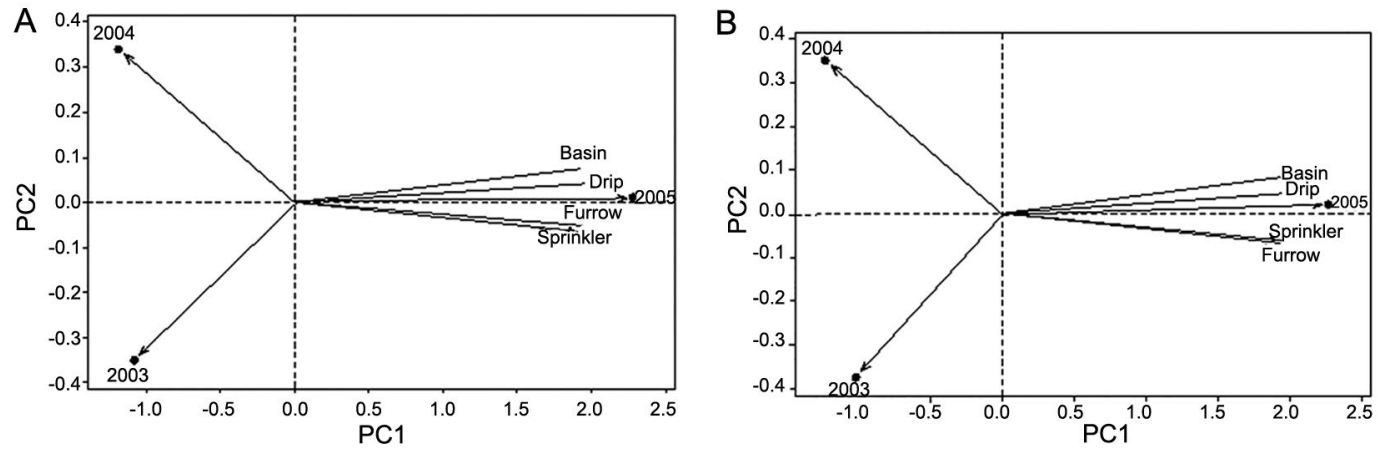

Figure 4 -The biplot of different irrigation methods in three growing seasons for (A) saffron stigma dry weight, and (B) water use efficiency. PC1 and PC2 are the first and second principal components, respectively. 
as well as the lower water consumption, IWUE and WUE values generally tended to be higher for the drip irrigation method. In 2004, the drip irrigation treatment followed by the sprinkler irrigation treatment had the highest IWUE and WUE values while, in 2005, the basin irrigation treatment ranked second after the drip method. The ratio of the maximum to minimum WUE was equal to 9.46 and 2.90, respectively in 2004 and 2005. The corresponding ratios were equal to 10.4 and 4.23 , respectively for IWUE in 2004 and 2005. Therefore, by adopting the appropriate irrigation method, the IWUE can be increased up to 10 times.

From 2003 to 2005, the amount of water consumed for drip irrigation method was equal to 600, 500, and $483.3 \mathrm{~m}^{3} \mathrm{ha}^{-1}$ showing a decreasing trend while there was an increasing trend for the corresponding values of IWUE as well as WUE (Table 5). Thus, generally speaking, both WUE and IWUE tended to decrease with increases in irrigation. Payero et al. (2008), in their study showed that the decreasing tendency of IWUE and WUE values in relation to irrigation is expected in arid and semi-arid regions. Table 5 also shows that, both IWUE and WUE are more closely associated with the irrigation method. Thus, IWUE and WUE had a matching behavior with the irrigation method. Accordingly, both IWUE and WUE can be used to estimate the water use efficiency of different irrigation methods in saffron farms. The results of multivariate analysis also confirmed that the highest WUE was found when the drip irrigation method was employed in 2005 (Figure 4B).

The results of the current study indicated that the highest stigma dry weight was produced by the drip irrigation method during all three growing seasons of the experiment. Furthermore, compared to the traditional irrigation system, less water was consumed by the drip irrigation method in each growing season. Therefore, due to less water consumption and more stigma dry weight production, it is suggested that the use of drip irrigation method can increase the efficiency of water use by up to 10 times. The cost imposed on farmers would be considered as the only disadvantage of drip irrigation method. Nevertheless, it should be taken into account that long-term use will compensate for increased deployment costs as a result of the saving in water consumption as well as the achieving of more yield.

\section{Authors' Contributions}

Conceptualization: Mollafilabi, A; Davari, K. Data acquisition: Mollafilabi, A; Davari, K. Data analysis: Amini Dehaghi, M. Design of methodology: Mollafilabi, A; Davari, K. Writing and editing: Amini Dehaghi, M.

\section{References}

Amini, M.; Ghoranneviss, M.; Abdijadid, S. 2017. Effect of cold plasma on crocin esters and volatile compounds of saffron. Food Chemistry 235: 290-293
Azizi-Zohan, A.A.; Kamgar-Haghighi, A.A.; Sepaskhah, A.R. 2009. Saffron (Crocus sativus L.) production as influenced by rainfall, irrigation method and intervals. Archives of Agronomy and Soil Science 55: 547-555

Azizi Zohan, A.A.; Kamgar-Haghighi, A.A.; Sepaskhah, A.R. 2006. Effect of irrigation method and frequency on corm and saffron production (Crocus sativus L.). Journal of Water and Soil Science 10: 45-54

Ghorbani, R.; Koocheki, A. 2017. Sustainable cultivation of saffron in Iran. p. 169-203. In: Lichtfouse, E., ed. Sustainable agriculture reviews. Springer, Cham, Germany.

Jafarzadeh, A.; Khashei-Siuki, A.; Shahidi, A. 2015. Modeling of climate change effects on saffron water requirement in south Khorasan province by GIS. Journal of Saffron Research 3: 163-174.

Kabiri, M.; Rezadoost, H.; Ghassempour, A. 2017. A comparative quality study of saffron constituents through HPLC and HPTLC methods followed by isolation of crocins and picrocrocin. LWT 84: 1-9.

Kafi, M.; Kamili, A.N.; Husaini, A.M.; Ozturk, M.; Altay, V. 2018. An expensive spice saffron (Crocus sativus L.): a case study from Kashmir, Iran, and Turkey. p. 109-149. In: Ozturk, M.; Hakeem, K.R.; Ashraf, M.; Ahmad, M.S.A., eds. Global perspectives on underutilized crops. Springer, Cham, Germany.

Karimiferezgh, M.; Khazaei, H.R.; Kafi, M.; Nezami, A. 2018. Comparison of the effect of irrigation levels and methods on leaf area and replacement corm production of saffron (Crocus sativus L.). Saffron Agronomy \& Technology 6: 279-290.

Khazaei, M.; Monfared, M.; Kamgar Haghighi, A.A.; Sepaskhah, A.R. 2013. The trend of change for weight and number of saffron corms as affected by irrigation frequency and method in different years. Journal of Saffron Research 1: 48-56.

Koocheki, A. 2004. Indigenous knowledge in agriculture with particular reference to saffron production in Iran. Acta Horticulturae (ISHS) 650: 175-182

Kyriakoudi, A.; Ordoudi, A.; Roldán-Medina, M.; Tsimidou, Z. 2015. Saffron, a functional spice. Austin Journal of Nutrition and Food Sciences 3: 1059.

Payero, J.O.; Tarkalson, D.D.; Irmak, S.; Davison, D.; Petersen, J.L. 2008. Effect of irrigation amounts applied with subsurface drip irrigation on corn evapotranspiration, yield, water use efficiency, and dry matter production in a semiarid climate. Agricultural Water Management 95: 895-908.

Razavi, B.M.; Hosseinzadeh, H. 2017. Saffron: a promising natural medicine in the treatment of metabolic syndrome. Journal of the Science of Food and Agriculture 97: 1679-1685.

Sereshti, H.; Ataolahi, S.; Aliakbarzadeh, G.; Zarre, S.; Poursorkh, Z. 2018. Evaluation of storage time effect on saffron chemical profile using gas chromatography and spectrophotometry techniques coupled with chemometrics. Journal of Food Science and Technology 55: 1350-1359.

Vahedi, M.; Kabiri, M.; Salami, S.A.; Rezadoost, H.; Mirzaie, M.; Kanani, M.R. 2018. Quantitative HPLC-based metabolomics of some Iranian saffron (Crocus sativus L.) accessions. Industrial Crops and Products 118 :26-29.

Yarami, N.; Kamgar-Haghighi, A.A.; Sepaskhah, A.R.; Zand-Parsa, S. 2011. Determination of the potential evapotranspiration and crop coefficient for saffron using a water-balance lysimeter. Archives of Agronomy and Soil Science 57: 727-740. 